prognoses is the most effective use of scarce resources' leads necessarily to the statement, as is implied, that 'more patients per unit of resources can be treated in this way than by any alternative approach'. Second, neither statement can be equated with efficiency (as is implied by the second sentence) and third, since efficiency is concerned with maximising social benefit from the available resources, then if society wishes to place a higher value on certain individuals or (more likely in the context of health care) on groups of individuals, then this will be and should be reflected in efficiency.

Such muddled thinking is but an example. The author seems not to understand the concept of efficiency nor to accept the notion of scarcity of resources. But since, as an economist, I accept both, I cannot recommend that readers of the JME devote their time-a scarce resource - to reading this book.

I have never before written such a negative review of a book. I hope I never have to again for it is not a pleasant experience.

PROFESSOR G MOONEY Institute for Social Medicine, Blegdamsvej 3, 2200 Copenhagen N, Denmark

\section{Surrogate Motherhood}

Martha A Field, 215 pages, London, £17.95, Harvard University Press, 1988.

In this readable yet scholarly book, Martha Field provides a welcome overview of the legal and 'human' aspects of surrogacy. In a compelling introduction she narrates vividly some of the real life conflicts which have arisen from surrogacy, culminating in the well-known case of Mary Beth Whitehead, who, after entering into a contract to act as a surrogate mother for William and Betsy Stern, refused to hand over the baby, after birth, to its biological father. The resulting conflict, which became known as the case of Baby M, brought surrogate motherhood to public attention in the USA and elsewhere.

The major part of the book consists of an examination of surrogacy and reflections on the law's response to it. Professor Field considers surrogacy in general and then looks in some detail at surrogacy contracts. Of its nature surrogate motherhood is impossible to ban effectively - indeed its very existence is hard to assess as it can be achieved without medical intervention. But contracts for surrogacy, which apparently emerged in the 1970 s, seem to raise new problems. How should society treat these contracts? The options available to a legislature are to ban all such contracts, making them illegal; to allow them but to make them completely or partially unenforceable by one or both parties; or to apply the usual principle of contract law and to enforce them accordingly.

The author examines considerations of public policy which might demand the outlawing of surrogacy and then analyses the true nature of surrogacy contracts. Are they contracts for sale? If so they must conflict with the legal provisions which prohibit baby-selling in most States of the Union. Are they contracts for services? If so it may be argued that they exploit women and commercialise child-bearing in an undesirable way - since they will usually involve the use of poorer, disadvantaged women by more privileged and affluent couples. A counterargument presented here is that legal prohibition of surrogacy would be unduly paternalistic since surrogacy can be and often is entered into freely - to the woman's advantage or for altruistic reasons.

An interesting feature of the book is the consideration of the constitutional aspects of surrogacy; does the US Constitution support the right to surrogacy through the 'right to procreate', through the fourteenth amendment, providing for 'equal protection', or through the application of the 'due process' clause to the notion of a man's right to have issue which is biologically his? Can the Constitution not be used to support the right of a surrogate mother not to be deprived of her child if she changes her mind and wishes to keep it? These arguments, though of varying effectiveness, are instructive, especially for public lawyers, but Martha Field concludes that they are unlikely to be helpful in the determination of surrogacy disputes.

She then examines the relevant factors which the courts may consider, apart from contract, in custody disputes between biological father and surrogate mother. The judgement of who is the 'better parent' is notoriously difficult and fraught, as the book ably demonstrates, with unconscious prejudices about life-styles and cultural norms - such as those demonstrated in the Baby $M$ case, where Mary Beth Whitehead's fitness for motherhood was judged and found to be inferior by $a_{\text {: }}$ predominantly middle-class judiciary and professional witnesses.

In conclusion, the autho $\bar{E}$ recommends that surrogacy contracts should not, on balance, be made illegal $\vec{T}$ but that they should be unenforceable against the surrogate mother if shछे changes her mind; she can then keep thechild, subject to returning payments received by her. In the absence of contractual considerations, the painfub dilemmas of custody of the child shoulक be resolved by adopting a number of clear rules - especially by a presumption that the 'primary caretaker' has a right to the custody of the child - in the casen of a newborn child usually the mother. Other rules, regulating visiting righto and financial obligations, are also suggested, so as to minimise the suffering and doubt of all parties buळ especially of the child.

These recommendations are cleas and the arguments leading to them well made. Some minor quibbles remain:the chapter which considers the effectof? new reproductive techniques on the family falls somewhere between arb adequate general discussion of the problems and a specific look at those linked with surrogacy; nor does the्f book examine the situation which willo presumably, occur increasingly - the mother's position where she provides as it were, merely a uterus in which $\$$ fertilised ovum is implanted and contributes no genetic material to the child she bears. Finally although the book deals with the 'human' issues, the author does not perhaps do justice to the ethical grounds for objecting tơ surrogacy. Subject to these minot criticisms, this book is an excellent and welcome addition to the literature on an important area of law and medicine.

MAUREEN MULHOLLANi⿱

Lecturer in Law, Faculty of Law

University of Manchester, Oxford Roads Manchester M13 9PID

Faces of Medicine: $A$ Philosophical Study

W J van der Steen and P J Thung, 236 pages, Dordrecht, $£ 38.00$, Kluwer Academic Publishers, 1988

This is an interesting book and ar unusual one. It is unusual, first, because although written from a 